\title{
The negotiation of meaning in EFL learning in the language laboratory
}

\section{David Rees}

\section{(2) OpenEdition}

\section{Journals}

Electronic version

URL: http://journals.openedition.org/asp/2867

DOI: 10.4000/asp.2867

ISSN: 2108-6354

\section{Publisher}

Groupe d'étude et de recherche en anglais de spécialité

\section{Printed version}

Date of publication: 1 December 1998

Number of pages: 283-309

ISSN: 1246-8185

\section{Electronic reference}

David Rees, «The negotiation of meaning in EFL learning in the language laboratory », ASp [Online], 19-22 | 1998, Online since 11 April 2012, connection on 01 May 2019. URL : http:// journals.openedition.org/asp/2867 ; DOI : 10.4000/asp.2867

This text was automatically generated on 1 May 2019.

Tous droits réservés 


\title{
The negotiation of meaning in EFL learning in the language laboratory
}

\author{
David Rees
}

\section{Introduction}

1 This paper presents a summary of the author's DEA research work (Bordeaux University, 1997) under the same title. The original research project measured more variables than are described here, and this paper concentrates only on the long-term and short-term information retrieval.

2 Foreign language learning and teaching have, through the years, been subject to much research and experimentation in the classroom. Learning can never be an exact science as the learners and teachers in each situation are different, and we still have much to learn about the social psychology and psychology of the learning and teaching processes themselves.

3 This particular piece of research is based on teaching English to French horticulture, plant science and landscape students. The teaching takes place in a language laboratory where interactive learning methods are used. It is the efficacy of this interactive system that will be investigated.

4 Before setting out the theoretical basis for this paper in the review of the literature, the terms used in the title "The negotiation of meaning in EFL learning in the language laboratory" require some explanation.

\section{Interaction}

5 Interaction is one of those words used widely with many meanings which can be used to describe almost any element of learning or teaching in the classroom, even to the point of the interaction between a reader and his book. Interactive methods, interactive materials and interactive learning programmes have become common words in teaching circles, and it is important to differentiate specific meanings. In this paper interaction is the 
process of communication (in English and/or French), both verbal and non-verbal, vocal and non-vocal, between non-native speakers of English. It implies that there is a two-way dialogue, and it includes the element of negotiation described below.

\section{Negotiation}

6 In EFL research, the word 'negotiation' can have different meanings: Pica and Doughty (1983, 1984), Porter (1986), Kramsch (1984), Rivers (1984) and Long (1981) use the term negotiation for the negotiation of meaning in a foreign language. It is in this sense that the paper refers to negotiation. This negotiation of meaning involves the repeating, rephrasing and restructuring of phrases between two or more learners to enable them to understand the meaning of the messages they are communicating.

\section{Research}

7 Having been taught to use an interactive method in the language laboratory at the Institut National d'Horticulture (INH), I found myself advocating this system to other teachers without being able to offer any objective proof of how effective this method was nor any theoretical basis for the supposed success of this method. It was the desire to validate the methods we were using that led to the choice of this research.

The research described in this paper is the attempt to measure differences encountered when using interactive lessons as opposed to non-interactive lessons. By using an interactive lesson and a non-interactive lesson for comparable groups of students, the author intends to measure the short-term and long-term differences in comprehension and memory.

9 The purpose of this study is an attempt to quantify the supposed benefits of the interactive learning procedures used at INH for language learning, and presupposes that it will be possible to measure differences as the result of a single 2-hour lesson. The measured item is the retention of information.

The paper will survey the literature in the field of foreign language acquisition, interactive learning, negotiation of meaning and memory. It will then introduce the learning environment before going on to discuss interaction and its use in the language laboratory. The test procedures will then be described before presenting the data. The paper will end with a discussion of the results and the author's conclusions of the research carried out.

11 It is not possible within a two-hour lesson to measure improvement in language ability, and this is discussed in more detail later on. The variables being measured should help us better understand the processes involved in interactive learning, and any extrapolation of the results to talk about language learning as a whole must be done with great care. The separation and testing of independent variables in the classroom situation is far from easy. I hope, however, that even if this research cannot claim to prove very much at the end of the day, if it leads to further questions and research is this field, then it has achieved at least one small step forward. 


\section{Review of the literature}

12 The research described in this paper belongs to the ESP field (English for Horticultural and Landscape 'engineers') and also, as it is for French students in France learning English, to the field of EFL. It is also centred in the learning-centred field of research. There is no magic, however, in ESP or EFL learning. The pedagogical principles of interactive learning in a language laboratory can be applied just as well in ordinary EFL or ESL learning situations.

\subsection{Interaction and Negotiation}

Task has been defined in many different ways, and for this paper the author uses the following definition:

[a communicative task is] a piece of classroom work which involves learners in comprehending, manipulating, producing or interacting in the target language while their attention is principally focused on meaning rather than form. (Nunan 1989)

Doughty and Pica (1986) looked at information gap tasks to see whether or not they facilitated second-language acquisition, and found evidence that a task with a requirement for information exchange was crucial to the generation of conversational modification of classroom interaction. They also found that the participation pattern, as well as the task type had an effect on the conversational modification of interaction, finding that most modification was obtained when the participants were non-native speakers (NNS) and when the participants had heterogeneous levels. They found, however, that group activities do not automatically result in the modification of interaction among the participants:

To be effective, group interaction must be carefully planned by the classroom teacher to include a requirement for a two-way or multi-way exchange of information. Thus, the teacher's role is critical not only in providing students with access to grammatical input, but also in setting up the conditions for successful second-language acquisition in the classroom. (Doughty \& Pica 1986)

\subsection{Native speaker to non-native speaker input and interaction}

15 Long (1981) tested how native speakers (NS) modify their speech when speaking to nonnative speakers (NNS). He identified two distinguishable phenomena, input, which refers to the linguistic forms used, and interaction, which refers to the function served by these forms such as expansion, repetition and clarification. The appellation of interaction is changed to negotiation in later research to avoid confusion with the wider use of interaction. Long (1981) found that whereas input could not be ruled out as facilitating second-language acquisition, it was the modification of interaction that was the most noticeable element.

16 One of the problems with input theory is that it deals with only half the interactive process; communication is about input and output. It is possible that if the reception of modified input or modified interaction assists EFL acquisition, then perhaps the production of modified output would be even more useful (Papagno \& Vallar 1992)

17 Pica \& Doughty (1985) had looked at NNS-NNS interaction and found that 
when non-native speakers engage in genuine communication with each other, as opposed to a native-speaker interlocutor, they appear to experience a greater degree of involvement in their negotiation for message meaning. models, i.e., a blind leading the blind situation. In fact they found that NNS-NNS groups were more grammatical than NS-NNS groups; Porter (1984) found that only 0.3 per cent of learners' errors were miscorrected by their partners. Her findings were interesting in that there was a lack of significant difference between NS and NNS input for the interaction variables repair and prompt. This is important in that it indicates that learners are capable of negotiation like NSs, Porter's findings confirm Breen and Candlin's (1980) contention that teachers should not assume that just because learners have not mastered the target language, they approach the task of communication in a naive and superficial way. Another interesting finding in Porter's study was that virtually no breakdowns in NNS-NNS communication occurred due to phonological problems. The NS, on the other hand, occasionally had trouble understanding his NNS partner. The point is that learners from the same native language background may serve as better interaction partners for each other than learners from different language backgrounds on the basis that their similar interlanguage phonologies will be comprehensible. Porter also found that NNS-NNS pairing produced more talking than NS-NNS pairing. If production practice is viewed as essential to acquisition, learners will benefit by practising with other learners rather than with NSs. It should be remembered that in an interactive lesson as taught at INH, the teacher corrects and helps the NNS-NNS pairs so as to avoid the naturisation that might occur and the fossilisation of errors.

An important point to note at this time is that heterogeneous groups could be more effective than homogenous groups as a greater degree of negotiation is required. The less the recipient understands of the speaker's communication, the more the speaker needs to adapt it to make it understandable. Alternatively, the poorer the input the recipient receives from a weaker partner, the greater the amount of negotiation needed to get to understand the meaning.

In regard to level differences, the finding was that learners got more input and better quality input from advanced learners than from intermediates, suggesting an advantage for practice with a higher-level partner from the perspective of quality and quantity of input. Thus teachers might wish to pair students of differing proficiency levels in the language classroom. (Porter 1984)

21 By the 1980 's, interactive teaching in ESL and EFL situations was becoming fashionable, and task-based learning situations designed to get students communicating in a meaningful way was the order of the day. As Allwright put it,

I hope to go well beyond 'get them communicating' to consider interaction in the classroom not just as an aspect of 'modern' language teaching methods, but as the fundamental fact of classroom pedagogy - the fact that everything that happens in 
the classroom happens through a process of live person-to-person interaction.

(Allwright 1984)

It was realised that by using communication, in solving communication problems, one does not merely practise communicating but also one extends one's command of the means of communication, the language itself. Although the idea was launched that NNS students could learn from each other, it met some opposition from teachers who had difficulty in seeing the transfer of their role from 'teacher' to 'manager', especially as this often meant that positive management meant keeping quiet to let the learners learn. What was also changing, and needing research, was the classroom climate or affective climate necessary for interactive learning. The roles change in interactive learning. To use the terms of transactional analysis, instead of the 'Critical Parent - Adapted Child' relationship (Harris, 1976) found in 'standard' teaching situations, the NNS-NNS situation could benefit from 'Child - Child' and 'Adult - Adult' roles. This changes the whole mood and affective atmosphere and hence phatic communication in the classroom. Again to quote Allwright:

We are no longer talking of teachers teaching and learners learning, but of everyone contributing to the management of everyone's learning (including their own, and including the teacher's, of course). (Allwright 1984)

\subsection{Remembering what was learned}

The next question facing researchers was what type of interaction is most beneficial to FLA and how does the process work? Also, how are new grammatical models and vocabulary, which are learned during interaction, processed and passed from the shortterm memory (STM) to the long-term memory (LTM) so that they can become part of the learner's language equipment.

Seliger (1977) studied adult ESL learners and compared learning ability with interaction type and quantity. He concluded that interaction type was a determining variable in the acquisition of a second language and that while placement test scores could not have predicted performance on final tests, measures of interaction could. In this case the differences of ESL and EFL learning are considerable, and one must be careful of the validity of information which is extrapolated from ESL interaction which is part of the natural environment and EFL interaction in the classroom. Seliger does, however, look closely at the retention or storage of acquired language skills. He sees memory working as a network whereby new skills or vocabulary are associated to (what he terms "subsumption") existing similar skills or vocabulary. But, in order to subsume new material within already existing cognitive networks, unique features or attributes of the new concept are often reduced or obliterated. Interaction, in the sense of negotiation, involves a high degree of repetition, and this repetition can help establish new linguistic concepts in the mind. Seliger says:

Within second language learning, overgeneralization errors resulting from L1 interference or the overextension of L2 rules can probably be traced to the obliterative effects which erase the contrastive features of one rule when it is subsumed under another already existing rule. Practice or further use of the language by the learner for his own purposes helps to distinguish the features of newly acquired rules whether they be rules of well-formedness or contextual appropriateness. (Seliger 1977)

and 
While it may seem obvious at first glance that practice has an effect on language competence, it should also be obvious that different kinds of practice have different effects on developing competence. Teachers have long been frustrated with the phenomenon of near perfect performance in formal drill in class and the lack of transfer of this performance to real communicative ability. (Seliger 1977)

Research on interaction has mostly used short-term tests to measure improvement, or has simply measured the discourse during interaction. It seems essential to measure the long-term transfer of learned skills from immediate use to permanent skill, while at the same time keeping a sense of proportion about what is being remembered and how it relates to language acquisition. As Slimani (1992) states:

It is amply acknowledged that learning a language is not merely a matter of recalling beads of items but rather coming to grips with the ideational, interpersonal and textual knowledge which is realised through effective communication in the target language.

The function of memory is, therefore, critical in the assessment of the long-term success or usefulness of interaction in the classroom. Research on interaction has mostly been descriptive or has used discourse analysis to describe the process of negotiation. The author has not found any work on interaction which also looks at the long-term memory of information learned during that interaction. If it can be demonstrated that negotiation of meaning leads to long-term storage of content (the interaction or task has a subject matter other than language itself, especially in ESP and EST (English for science and technology)), then perhaps experiments can be devised which will demonstrate the longterm storage of language skills learned during the interaction process; i.e. those new grammatical models learned from either the core material or from one's partner which have been received as input (perhaps several times), practised as output, adapted and modified to the situation, and repeated until mastery is obtained.

As mentioned previously, it is has been proved that NNS-NNS two-way interaction, when based on a specific task, produces negotiation of meaning, and that the negotiation of meaning enhances EFL acquisition. The tests used, however, for much of the research, were short-term memory (STM) tests. It should, therefore, be asked, whether or not EFL acquisition by negotiation of meaning leads to long-term acquisition of the subject matter and the associated language skills.

Language learning is a complex matter as far as memory is concerned. Firstly there is the matter of separating content from technique: content includes useful ESP vocabulary as well as comprehension of the subject matter; technique includes new grammatical forms and constructions. Secondly there is the matter of the senses used in language learning; phonological memory stores the sound and stresses of a word; necessary for the comprehension of the word when it is spoken, and necessary for the oral production or reproduction of the word in order to communicate. Lexical memory stores the spelling, perhaps etymology and word family of the word; it associates the word with synonyms to help create a 'meaning' for the word. It also might link the foreign word with the mother tongue word. Graphical memory stores images and positions, and this memory function is sometimes used for vocabulary storage by mnemonic association, whereby a word is associated with an image to assist storage and retrieval of the word. 


\subsection{Comprehension and recall} on transformational linguistics (Chomsky 1957, 1968). Sentences are assumed to have both superficial and underlying (deep) structures. The surface structure characterises the phonological shape of the sentence, but the deep structural information is presumed necessary for characterising sentence meaning. Comprehension thus involves the recovery and interpretation of the abstract deep structural relations underlying sentences. Bransford and Johnson (1972) studied the contextual prerequisites for understanding, and found that subjects create semantic products that are a joint function of input information and prior knowledge. Subjects require retrieval cues, provided, for example, by the images seen from a video which can be associated with the meaning of the narration. They did find, however, that comprehension per se does not necessarily guarantee subsequent recall. NS-NS pairing, for example, should provide a high level of comprehension, since they are speaking in their native language. The author suggests, however, that NNS-NNS pairs, who need to negotiate meaning will have, even though their comprehension might be poorer than an NS-NS pair, improved long-term recall. The negotiation should provide repetition as well as different semantic structures and also the provision of synonyms, all of which should provide the cues necessary for long-term recall. Bransford and Johnson's work demonstrates the importance of avoiding EFL tests where previous knowledge can affect results. Prior knowledge, which effects the recall of new knowledge, should be avoided if one wants to test language acquisition objectively.

\subsection{Phonological memory in EFL learning}

The accurate repetition of foreign words shows a strong correlation with performance in EFL learning. The ability to represent unfamiliar phonological material in working memory underlies the acquisition of new vocabulary items (Service 1992). This repetition can either be internalised, as in silent repetition, or externalised as in interactive task work where new vocabulary is vocalised. When one listens to a foreign word which is new, it enters a short-term store. Because the contents of the store fade over a limited period of time, the maintenance of the word phonology and meaning is achieved through refreshing the phonological trace by cycling it through the articulatory rehearsal loop (ibid.). This work should confirm that negotiation of meaning, which involves high levels of articulated repetition, should lead not only to FLA, but also that the acquired material should largely pass from STM to LTM. This process of passing new vocabulary into the LTM via the articulatory rehearsal loop is particularly important for vocabulary where there is no memory hook, such as a similar etymological root between the native and foreign word. Repetition would be, therefore, more important between the words 'salle de bains' and 'toilet' since the etymology is different. This is fine for remembering the meaning or translation of the word, but the phonological trace between 'environnement' and 'environment' is just as important so that the correct pronunciation is remembered, so repetition is useful for all new vocabulary. The findings of Service are confirmed by Papagno and Villar:

There is a close relation between the acquisition of vocabulary and immediate repetition of auditorily presented non-words, a task that is likely to require the temporary storage of the non-word. The articulatory rehearsal process refreshes 
the phonological trace held in the phonological short-term store, preventing its decay. The rehearsal process is involved in the acquisition of items for which no pre-existing lexical-semantic representations are available in long-term memory.

In conclusion, it has been shown that in interactive EFL learning situations, the memorisation of the lesson content and vocabulary is highly dependent on the context of the information, prior knowledge and the repetition of new vocabulary.

\section{The Setting}

\subsection{The institution: INH}

Institut National d'Horticulture (INH) is situated in Angers in the Loire Valley. It is the pole national of horticulture in France, and attracts candidates from les écoles préparatoires, from students with a BTS as well as students with a DEUG or maitrise in biology or biophysiology. The students stay for three years and choose from one of two main streams, horticulture or landscaping, and specialise in their third year between a variety of options. Upon completion of their studies and a mémoire, the students leave as engineers. The present enrolment is 240 students. This will rise to 450 students by the year 2002 when a new programme to teach Bac $0+5$ is integrated into the existing Bac $2+3$ system.

\subsection{Language teaching for future engineers}

33 The goals of the language department correspond to the practical and pragmatic goals of the establishment. It is not intended that an engineer follow a purely academic course of instruction. An ideal engineer has mastered the techniques and tools whereby he can approach and solve problems on site because, even though the subject matter might be new, the methodology is the same.

One of the skills an engineer needs to work in an increasingly Europeanised France, is to be able to communicate in other languages. Our pragmatic 'engineer' approach to language teaching focuses on successful communication. Within any learning system, choices must be made. With only two hours per week per language (one to three languages) of formal teaching, some elements of language skills must be sacrificed for others. Our goal is communication. To this end students learn to comprehend and speak; and these are both centred around the specificity of the scientific language required. Students typically spend $30-40 \%$ of their time working alone or with a partner on comprehending video-based texts, and $60-70 \%$ of their time communicating with a partner (which involves both comprehension and oral production). There is virtually no studying of written texts (apart from video transcripts), translation or written work. Our aim is that students will leave INH ready and willing to communicate; we do not pretend that they are entirely accurate phonetically - phonetic accuracy being perhaps an important requirement for a future teacher of English, not a horticultural engineer; nor will they be able to write without some grammatical mistakes: they have computer and book models to follow and adapt as necessary. Apart from the students who voluntarily train for TOEFL in 'extra' classes, there is no deliberate teaching of grammar at all. Experience shows that most students arrive from 'prepa', 'maitrise' or 'BTS' with a 
sufficient understanding of grammar to enable them to analyse what they are doing. Unfortunately some of them arrive having limited conversational ability.

\subsection{The staff and teaching practices}

The language department staff consists of the head of department, Robert Tuffigo (professeur agrégé), myself (enseignant contractuel, B.Sc. Hon's., PGCE) a vacataire for Spanish and a 'vacataire' for German. The department is set to expand considerably as not only will numbers increase from 240 to 450 , but a second foreign language (at present optional) will become mandatory.

All English lessons and one in every two German and Spanish lessons are taught in our language laboratory. The method employed is one created by Robert Tuffigo. This method consists of interactive task-based learning using multi-media input. The material is usually, but not always, scientifically or horticulturally based.

When I started teaching at INH in 1994, Mr Tuffigo trained me not only in the technical handling of the laboratory, but also in using his interactive methods. I had no previous experience of using a language laboratory. I was immediately impressed by two things: that the students really enjoyed what they were doing; and the apparent ease with which they spoke or at least tried to speak. There were no embarrassed silences; they forged ahead with their communication. And myself as teacher? I soon learned to resist the temptation of talking, and to simply listen in as the students communicated. The better the lesson plan, or the preparation of the material, the less I had to do. I became a resource to be used, a behind-the-scenes stage manager. Obviously I would correct and assist, but would always avoid the negative, critical fault-finding that can stop communication cold.

It was my enthusiasm for the efficacy of this interactive learning that led to the subject of this research. Firstly, however, it may be useful to describe the laboratory itself and a typical lesson in the laboratory.

\subsection{The language laboratory}

The language laboratory is set up in the recommended IALL (International Association for Learning Laboratories) horseshoe or $\mathrm{U}$ pattern for interactive learning so that the students can face each other. If the laboratory is used for individual work, guided learning or phonetic development, then a non-interactive layout with carrels is advised. The material is a Tandberg IS 10 with 24 posts. Each position has an in-built tape recorder with headphones and there is one television set per two posts. The teacher is in the gap of the ' $U$ '. From his position he can control the selection of groups, pairing, the transmission of video or audio recordings and the transmission of live cable or satellite television.

\section{Design and methodology}

\subsection{Objectives}

Identifying, separating and testing variables involved in the learning process in classroom-based research is a complicated job. The first attempt to provide useful data on 
interactive versus non-interactive learning was not successful and Test 1 was abandoned. Test 2 was never used. Test 3 avoided some of the previous design errors and hopefully throws some light on some aspects of the interactive learning process. This research is itself heuristic, in that one learns from one's mistakes and attempts to improve the design and methodology for the future. The variables involved in learning are not numbers from throwing a dice or something easily graspable; the variables encountered in the learning process are inevitably inter-related, complicated and sometimes difficult to measure. However clear the objectives may be, putting them into a well-designed test is not always easy.

The intention of the project is to teach some groups in an interactive way and other comparable groups in a non-interactive way. Once each group has received its interactive or non-interactive lesson, there is an immediate test which is classified as a short-term information recall test. This should provide data on how much of the information has been understood and is in the short-term memory.

Four weeks to the day after the lesson, the groups are tested again. This time they receive the same multi-choice questionnaire to measure their long-term information recall. Once the tests are completed, it is hoped that the results will indicate whether or not LTM differences can be observed between the interactive and non-interactive groups as far as the aforementioned variables are concerned.

\subsection{Variables}

Learning is a complex subject full of interrelated variables. There are many theories and explanations of how a foreign language is acquired. One of the problems in testing learning is to isolate the variables involved. As mentioned previously, the first tests failed to isolate the elements required for measurement in interactive learning, and it was only the third test that successfully (in the author's opinion) got close to avoiding some of the complications of what is being measured. The main hurdle is that one does not know what previous knowledge and what previous skills are in place in the student's mind, and therefore how can one measure progress in knowledge or progress in skill if one cannot determine the starting position? This problem was overcome by using new knowledge in order to start the students from the same position.

The variables that are measured are short-term information recall and long-term information recall

\section{Short-term information recall}

Information is considered to be the content or subject matter of the lesson. Information is intended to be new information. If the student already has the information stored in his memory, then one would be testing long-term recall from previous lessons or reading, and not short-term recall. Information is considered to include grammar, in that grammar is there to make the information understandable.

\section{Long-term information recall}

Long-term recall is considered the memory that is functioning after a period of 24 hours (in fact the tests were carried out after 4 weeks). 


\subsection{Methods chosen to test the variables}

\section{Introduction to tests 1,2 and 3} models, the problem was how to create the same lesson for the interactive and noninteractive groups while at the same time avoiding the 'dual competence' advantage of sharing information. It was in order to avoid this problem, and also the problem of 'prior knowledge', that it was decided to use a fairy tale, written by the author, which would be, in effect, a completely new story whereby no student could have any prior knowledge, nor could they use any prior knowledge to inform each other about the subject matter. Interaction, or negotiation, between paired students, should according to the hypotheses, lead to a better understanding and better memorisation of the material itself. This would be due to the repetition and negotiation involved in paired students. This would then be comparable to standard interactive learning where two things should 
occur: the subject matter should be better understood and memorised; the language skills should be better developed.

Test 3 is not able to measure the increase in global language skill as this would require the long-term testing of skills over perhaps one or two years, as well as requiring the measurement of specific skills levels before the learning programme was started. What Test 3 attempts to measure is the effect of interactive learning on the memorisation of content or subject matter.

The content element is obviously important, as the interactive learning method used at INH is always content-based. The foreign language is simply the tool used to transmit the subject matter; it becomes the means instead of the subject itself. Students get involved, for example, in learning about and discussing closed-production units in Holland to avoid pollution, and their concentration is based on the subject matter. Ideally they forget they are in a language lesson. If we were concentrating on the metalanguage, i.e., use of the passive in research, then the language itself becomes the focus of the lesson, which is something we deliberately avoid. If subject matter is better retained through interactive learning, then this has consequences for the learning of all subjects, not just languages. A positive long-term information recall result for interactive learners would favour the interactive problem-based, tutorial style of learning as opposed to the non-interactive lecture type of learning. The subject matter of Test 3 could be considered frivolous. It is not the frivolity of the subject matter that makes it a good or bad example lesson, it is that it is based on new information that thereby makes the test methodologically acceptable. However, it must be remembered that a normal lesson would take place in the domain of expertise of the students, therefore in a normal lesson the students' prior knowledge would facilitate further learning. This is an example of how difficult it is to find an acceptable medium between methodological acceptability on testing grounds, and classroom research that should try to replicate real learning situations.

\section{The story of Shagal and Miranda}

"The story of Shagal and Miranda was written" by the author and was very loosely based on the story line of J.R.R.Tolkein's The Hobbit. The story has the typical fantasy elements of a fairy tale. There is a hero, a heroine, monsters and danger as well as magic and strange alien places. The hero and heroine fall in love, the hero having defeated the various enemies that cross his path, and having rescued the heroine from the clutches of evil dwarves as well as from the web of giant spiders. The hero and heroine marry and live happily ever after to finish the story.

The story takes place in a strange land and is geographical by nature, in that the hero and heroine travel to various parts of this land. The author drew a plan to accompany the story. This plan has four different versions: the total plan with all the information (appendix 29), a base plan which outlines the main geographical elements (appendix 30) such as the lake, sea and mountains; the base plan with half of the information included (appendix 31) and the base plan with the other half of the information included (appendix 32).

\section{The functioning of Test 3}

a) Interactive groups

Interactive groups are split into two equal groups, A and B. Sub-group A are given a base plan which includes half of the information necessary to complete the plan. Sub-group B 
are given the other half plan. Sub-groups A and B are paired together so that each student has a partner from the other group. headphones and the texts and all the plans are taken in by the teacher. The students are then given a question sheet (appendix 37-38) to answer. There is no time limit, and the students leave once they have finished the questions. The students leave the class with neither text nor plan and are not aware that they will be tested again on the same subject.

\section{b) Non-interactive groups} plan. The teacher then gives the students all the necessary information to complete the plan. The students are not allowed to ask each other for information, only the teacher. The teacher responds not only to requests for repetition, verification and explanation, but also responds to what he perceives to be lack of comprehension, i.e., when he sees that a student has drawn something in the wrong place, he tells him (audible to the whole class), and never shows him what correction is necessary.

Once the plans are complete, the teacher gives the students the correct full plan and the students compare what they have drawn to what they should have drawn. phrases and explains the story and responds to any requests from the students for further information or explanation. The students still have their full plan to help them follow the geographical progress of the story. The students are told not to take notes nor to write down the text. The teacher then tells the group the story of Shagal and Miranda. He repeats words and Once the story has been completed, the teacher collects in all the plans and gives the students the question sheet to complete. There is no time limit, and the students leave once they have finished the questions. The students leave the class with neither text nor plan and are not aware that they will be tested again on the same subject. 


\section{- Students from INH (Year 1 groups 1, 2 \&3; Year 2 groups 1,2 \&3; Year 3, five option} groups)

71 and landscaping students are in group 3. Groups 1 and 2 are selected according to their level in computer science. There is no reason for the level of English ability between these groups to be disparate. The third year consists of 5 groups of 4 to 14 students per group. These groups are established according to the third year option the student has chosen. 
First and second year students have regular English lessons once a week (50-55 hours per year), third year students have more irregular lessons due to their visits, symposiums, etc. (30-35 hours per year).

All INH students come from a similar educational level in that they have been through École préparatoire, BTS or Maitrise de Sciences before taking an entry exam into INH. Their levels of English can vary considerably, especially upon arrival, since some have done very little English, having chosen German or Spanish as a first language, and others have worked abroad and arrive with a high level of performance in English.

- Students from the Faculty of Science, Angers University (MST Year 1 groups 1 \& 2; MST Year 2 groups 1 \& 2)

These students are studying for their Maitrise Science Technique in biophysiology. There are 16-18 per group. The groups are divided alphabetically, and therefore the level of English between the groups should be similar.

- Students from the Faculty of Language, Law and Social Sciences, Angers University (CAPES groups 1 \& 2)

These students are in their first or second year of English CAPES studies and come to INH for speaking and conversation practice in the language laboratory. They all have a high level of English.

\section{Group comparability}

In order to compare the English ability levels of the different groups, they were all tested (excepting the INH third year groups) with TOEFL. Although TOEFL has several drawbacks (American English when most teaching at INH is in British English, difference between 'correct' and 'functional' grammar, etc.), it was chosen as the easiest and most reliable indicator of comprehension, grammar and vocabulary skills. It is understood that TOEFL is not considered by some scientists to be a reliable indicator of English proficiency, but INH approves of its use as a useful if not perfect measure. Perhaps in the future alternatives will be available. Not all INH third year students had taken or were going to take TOEFL and it was decided not to impose this on this already hard-worked group. In order to compare similar groups for two different situations (interactive and noninteractive learning), a minimum of two pairs per test group were necessary. All groups are taught by the author, therefore the lessons would be run as identically as possible.

The group TOEFL scores were considered close enough within each institutional year band, that no group was excluded due to its TOEFL score.

\section{Groups for Test 3}

For Test 3 , the following groups were chosen

- Comparison between INH Year 1 groups 1,2 and 3

- Comparison between INH Year 2 groups 1, 2 and 3

- Comparison between MST Year 1 groups 1 and 2

- Comparison between MST Year 2 groups 1 and 2

INH year 3 groups 1 and 2 were tested first in order to check out and practise the interactive and non-interactive lessons themselves and to check the functioning of the equipment.

\section{Group comparison}



necessary to see whether or not they are sufficiently similar to each other. The raw data are their adapted TOEFL scores from which the standard deviation of each group is found. The groups within each year group were not found to differ significantly in their TOEFL scores, and were therefore considered acceptable for testing.

\subsection{Hypotheses}

81 If a subject is discussed, then it should be easier to remember the content of that subject than a subject which is only heard. Discussion involves repetition and involves the negotiation of meaning of those elements that are not at first understood. Discussion should lead to a full understanding of the subject material. In the interactive learning groups there should be very few barriers to negotiating meaning. The pairing of one student with another student provides an environment in which both students are obliged to communicate (otherwise there is silence and nothing is learned) and where communication should be easy to perform as the rest of the peer group is not listening and hence there is no embarrassment about making mistakes in public.

New vocabulary will be vocalised as well as listened to. NNS-NNS pairs negotiate the meaning of the material which involves vocalisation and interactional modification. It is suggested that the vocalisation, repetition and modification elements involved in interactive learning should reinforce the passage of the information and vocabulary from the short-term memory into the long-term memory (Papagno \& Villar 1992; Service 1992; Pica, Young \& Doughty 1987)

In NS-NNS groups, i.e., groups taught by a NS teacher, students will individually provide much less discussion (as only one discussion can go on at a time, as opposed to the interactive group where there can be twelve simultaneous conversations), and any discussion will be with the teacher, not with other NNS students. There is very little negotiation of meaning and virtually no vocalisation for most students. The teacher does most of the talking, and the students do not need to negotiate meaning as the teacher will understand first time, even if the message was syntactically incorrect. Some students, due to the embarrassment factor of making mistakes in front of a peer group, will avoid indicating a lack of understanding, and will therefore miss some information. As the speaker (the teacher) is an NS, the information given will be accurate and should therefore be easy to understand. In spite of this, the author believes that the low level of repetition and negotiation will lead to a weaker initial understanding of the information (Allwright, 1984 \& 1983; Seliger, 1977). Therefore:

\subsubsection{Hypothesis 1}

Interactive groups (NNS-NNS) will have higher STM information recall scores than non-interactive (NS-NNS) groups

Negotiation of the subject matter should lead not only to higher STM scores, but also to better LTM scores. Vocalisation includes another sense to that of hearing, and this also, according to Service, 1992 and Papagno \& Vallar, 1992, should assist in the process of information passing from STM to LTM. If H1 is found to be valid, then interactive groups will already have higher scores than non-interactive groups, therefore hypothesis 2 is expressed in terms of the degree of memory loss rather than the total score. Therefore: 


\subsubsection{Hypothesis 2}

The weakest students *(lowest $50 \%$ as measured by TOEFL) in the interactive groups will score significantly better in the ST information recall test than the weakest students* in the non-interactive groups, in comparison to their expected results based on their TOEFL scores.

\subsection{Type and Form of Data}

\section{Data collection}

Hypotheses 1-3 can be tested using quantified data, i.e. test scores. Group comparisons can also be made quantitatively by using their TOEFL scores. This provides the opportunity for quantitative statistical analysis.

\section{TOEFL data}

In order to compare group language ability it was decided to use their TOEFL scores. TOEFL is a multiple-choice test, each answer having 4 possible answers of which one is correct. The calculation of the TOEFL score uses a special transformation chart and calculation to arrive at the final TOEFL score, the maximum being 660 . In that there is a $25 \%$ chance of having the correct answer for any question, it was decided to remove the chance element from the score. $25 \%$ correct answers produces a TOEFL score of 330 , and it was therefore decided to create an adapted TOEFL score, TOEFLa, which is the real score minus 330. Although this increases the standard variation for each group, it was considered statistically more correct.

Data use regarding the hypotheses 
Hypothesis 1: the information STM scores were compared statistically (t-test) between interactive and non-interactive groups within each test group.

Hypothesis 2: The LT information recall score was subtracted from the ST information recall score. The amounts of loss were compared (t-test) between interactive and noninteractive groups within each test group.

4 Hypothesis 3: The scores of the 50\% of weakest students according to their TOEFLa scores were separated from the other scores. In order to measure improved learning by one group over another, it was decided to measure the ST information recall of these two groups and to measure the correlation coefficient between their test scores and their TOEFLa scores. If the interactive group weaker students have better scores for information recall, then the correlation coefficient should be lower for this group than for the non-interactive group. This was also charted graphically.

\section{Test procedure}

Having tested the interactive and non-interactive lesson with the third year groups, the lessons went as planned with all other groups without any problems.

The teacher attempted to keep the lessons as similar as possible, although it is inevitable that this variable cannot be identical for each lesson. Little difference was found between the procedure for each group except for the CAPES students who were much quicker for both the interactive and non-interactive groups. For these two groups there was noticeably little negotiation of meaning.

The groups were re-tested 4 weeks to the day after their initial tests. Each group was told that this re-testing (which was obviously not a normal part of language teaching, and therefore suspicious) was for the author's research; the groups were therefore quite happy to complete the tests. Normally students dislike being tested without prior notice, and could react negatively to a 'surprise' test being given. The groups were informed that the scores would not count towards their continuous assessment mark for the year. This might mean that the test was not taken as seriously as if it were included in their assessment scores, but the author considered it better to do this than to run the risk of students who felt the procedure to be unfair. It was, at least, the same situation for everyone. The students were spaced out and no talking was allowed. Dictionaries were available for help, but were not used much, as the students had already seen and understood the same questions before.

9 The first group to be re-tested was INH Year II group 3. The students were given the map to fill in and the question sheet at the same time. The question sheet provided a great deal of information which helped the students fill in the map. For this reason this group was cancelled from the results, and further testing was carried out with map completion first. After these were collected, the question sheets were handed out.

9 The teacher was present for all groups except for the testing of MST Year I who were all tested together in the presence of the department's technical assistant. In spite of receiving instructions to inform the group of the reason for the re-testing, this instruction was not given. The group was, in consequence, unhappy about being tested, thinking that this was a surprise test, and thinking that this would count towards their year marks. Upon questioning the technician, there was apparently considerable communication between the students. It was therefore decided not to include these two groups in the results. 
100 There was considerable interest from the students afterwards to know their 'memory' scores and to know the results of the research regarding the interactive and noninteractive groups, and therefore all groups were given an explanation for the research and a summary of the results.

101 In that most of the INH students had also undergone Test 1 with its LTM test as well as Test 3 with its subsequent LTM test, there was the suspicion afterwards that all lessons were part of some research procedure. It is advisable to avoid too much research testing of the same groups, so that the groups act in as normal a way as possible. Even though the reaction to research testing might be positive, the very fact that the students think that the test is for research purposes could easily affect the results. It was therefore decided to avoid testing as much as possible in the future so that the students would be 'naïve' of any follow up tests.

\section{Validation and summary of results}

\section{Hypothesis 1}

Interactive groups (NNS-NNS) will have higher STM information recall scores than non-interactive (NS-NNS) groups

All interactive groups showed higher STM information recall scores than non-interactive groups. Only two out of four comparisons were statistically significant (cf.table 1).

Table 1. Summary of t-test for hypothesis 1

\begin{tabular}{|l|l|l|}
\hline Group comparison & means & $\mathbf{p}=$ \\
\hline INH $1.1 /$ INH 1.3 & $26.3 / 23.9$ & n.s. \\
\hline INH $1.2 /$ INH 1.3 & $29.1 / 23.9$ & $1 \%$ \\
\hline \hline INH $2.1 /$ INH 2.2 & $27.2 / 24.9$ & n.s. \\
\hline MST 2.1 / MST 2.2 & $23.5 / 20.5$ & $5 \%$ \\
\hline
\end{tabular}

\section{Hypothesis 2}

Interactive groups will demonstrate a lower degree of memory loss (STM minus LTM) as marked in the information recall test than non-interactive groups.

Two interactive groups showed lower memory loss than non-interactive groups. These were statistically significant. First year INH groups showed no noticeable difference. No clear differences were seen in any of the groups (cf. table 2).

Table 2. Summary of t-test for hypothesis 2

\begin{tabular}{|c|c|c|}
\hline Group comparison & \% memory loss & $\mathbf{p}=$ \\
\hline INH $1.1 /$ INH 1.3 & $29.3 / 29.3$ & n.s. \\
\hline
\end{tabular}




\begin{tabular}{|l|l|l|}
\hline INH 1.2 / INH 1.3 & $21.6 / 29.3$ & n.s. \\
\hline INH 2.1 / INH 2.2 & $14.7 / 32.9$ & $1 \%$ \\
\hline MST 2.1 / MST 2.2 & $17.4 / 39.5$ & $1 \%$ \\
\hline
\end{tabular}

\section{Hypothesis 3}

The weakest students *(lowest $50 \%$ as measured by TOEFL) in the interactive groups will score significantly better in the ST information recall test than the weakest students* in the non-interactive groups, in comparison to their expected results based on their TOEFL scores.

INH Year 1 shows no clear sign of difference. INH Year 2 and MST show clear signs of difference between interactive and non-interactive groups (cf. table 3).

Table 3. Summary of correlation coefficients for hypothesis 3

\begin{tabular}{|c|c|}
\hline Group comparison & Correlation coefficient \\
\hline INH 1.1 (interactive) & 0.614 \\
\hline \hline INH 1.2 (interactive) & 0.044 \\
\hline INH 1.3 (non-interactive) & 0.636 \\
\hline INH 2.1 (interactive) & 0.061 \\
\hline INH 2.2 (non-interactive) & 0.138 \\
\hline MST 2.1 (interactive) & 0.014 \\
\hline MST 2.2 (non-interactive) & 0.364 \\
\hline
\end{tabular}

\section{Discussion of Results}

Hypothesis 1 - Interactive groups (NNS-NNS) will have higher STM information recall scores than non-interactive (NS-NNS) groups

The hypothesis is accepted statistically for half the comparisons. The other two comparisons, although not statistically significant show better scores for the interactive groups in comparison to the non-interactive groups. It is fairly clear that the interactive learning situation does have an immediate effect on recall.

It should be noted that this hypothesis is measuring the short-term recall of the information communicated during the lesson. It is possible that the short-term information recall is better for interactive groups than for non-interactive groups, but this possibly has nothing to do with the acquisition of a foreign language and its associated vocabulary and language skills. ESP learning, especially when using interactive or communicative techniques, concentrates on a subject matter, not on the metalanguage 
of a foreign language. The foreign language, in this case, is simply the means with which the information is transmitted. The question of whether or not one can extrapolate from information recall to language acquisition will have to wait for further research in this area; it is, however, encouraging to see such positive results from a single 2-hour lesson.

Hypothesis 2 - Interactive groups will demonstrate a lower degree of memory loss (STM minus LTM) as marked in the information recall test than non-interactive groups

As in hypothesis 1, the hypothesis is accepted statistically for half the comparisons. One interactive group in INH Year 1 had the same level of memory loss as the non-interactive group, but the other comparison groups, INH Year 2 and MST showed strong statistically significant differences. The INH 1.1 group was the only group not to receive its second (LTM) test in the language laboratory. As it was considered important to test the groups exactly the same number of days after the initial lesson, and as this group was not available for English on that day, they were tested just before their first lesson in crop protection. This possibly led to a certain amount of rushing the test by the students.

In general, the results are strong enough to demonstrate that the interactive learning technique used does have immediate consequences on long term recall. This confirms previous work on repetition and memory (Service 1992; Papagno \& Villar 1992). In the same way as in hypothesis 1 , care should be taken to avoid extrapolating results from the long-term recall of information learned in a foreign language to the acquisition of that language itself. Once again, the results are encouraging when one considers that they are the result of a single two-hour lesson.

114 Hypothesis 3 - The weakest students* in the interactive groups will score significantly better in the ST information recall test than the weakest students* in the non-interactive groups, in comparison to their expected results based on their TOEFL scores. *(lowest $50 \%$ as measured by TOEFL)

115 INH 1.1, the group previously mentioned for having taken their second test in different circumstances than other groups, have the only result contrary to an acceptance of this hypothesis. There is a marked difference between interactive and non-interactive groups, suggesting that interactive groups do help the weaker students rise above their expected performance level. This is a very interesting area to continue to research. It is already known that interactive lessons where pairing is used greatly increases the active speaking time of weaker students, and this, combined with the importance of the articulatory rehearsal loop (Service 1992), should mean that weaker students in particular benefit from interactive learning. It could also be that an interactive learning environment is more motivating for weaker students than traditional methods they might have encountered at college or lycée. Given the number of students arriving at INH having studied a language other English as their first language, it is very important to get these students up to level in the shortest possible time.

\section{Conclusions}

\section{Implications of results for further research}

What interests the author is action research, that is to say research that has a direct and perhaps immediate effect on the learning techniques and lesson planning of EFL and ESP programmes. There is a great deal that can be done to apply existing and future research 
to the classroom. France is going to require more and more engineers and professionals with competent communication skills. ESP students already have a great deal to learn in their particular subject matter, and language learning is often a secondary consideration. It is therefore our duty not only to inspire our students, but to apply research and to continue to research directly in the classroom for the benefit of the students for whom we are responsible now.

117 The results of the experiments carried out are evidently significant enough to indicate from these exploratory tests that interactive learning methods do make a difference to the retention and recall of information by students. This is sufficient to inspire further research. There are perhaps two main directions to follow in any follow-up research work:

\section{Discourse analysis}

During the present research, students were recorded in the language laboratory during the experiment. Transcripts of the communication between students gives some idea about how interaction, and particularly negotiation, works. The experiment itself, for methodological reasons, was different from standard teaching techniques in the language laboratory. In the future it would be interesting to study the transcripts of tapes of normal interactive lessons. Discourse analysis could then be used to distinguish more clearly the elements of negotiation used during lessons. This could be studied for students with different levels of ability in EFL as well as for different lesson types. In other words it might be possible to analyse the effects of a particular type of lesson in terms of the type, quality and quantity of negotiation. This could either be carried out in a qualitative, descriptive way or in an objective analytical way whereby negotiation elements could be scored and quantified. This offers exciting possibilities for testing pedagogical approaches as well as testing pedagogical materials. The same research could be undertaken in different languages to see whether or not there are differences of negotiation technique or style between English, German and Spanish.

\section{Interactive methods over time}

The results obtained from this experimentation were from a two-hour lesson. One of the problems in measuring the results was due to the necessity of avoiding previous knowledge and the impossibility of measuring advances in English acquisition (in terms of technique). A longer-term study would offer the opportunity of studying particular abilities or techniques that could be tested prior to and after interactive teaching methods over a year or even more. This would necessitate the measurement of control groups in another establishment that was using more traditional teaching techniques.

The present short-term study measured the retention of information of the subject matter which, as pointed out previously, does not necessarily indicate acquired language skills. A longer-term project could study language acquisition itself in terms of the effects of interactive learning. A comparison project between different establishments is not only sensitive politically, but would also need to use establishments with the same linguistic goals. Our goal at INH is communication, therefore we are interested in measuring advances made in comprehension and oral skill; another establishment might focus on reading and writing skills and would therefore want to measure different elements of ESP acquisition. However, in order to achieve the long-term goal of this study, which is to evaluate the benefit of interactive learning in the language laboratory, some comparison projects will certainly be necessary. 


\section{Negotiation as an art}

As mentioned in the introduction, media and computerised language laboratories. An investigation on a region level would be interesting to evaluate the actual use of these laboratories, and to see how they are or are not being used by language teachers. The use of interactive methods in the language laboratory needs to be, in the author's opinion, explained and marketed to language departments across France, from collège to École nationale. With this in mind, the author has submitted a project to 'IDEES 1998' for funding to create a language lab 'interaction pack' to explain the method to teachers and provide teaching samples that they can use to then go on to create their own interactive teaching materials. If this project is accepted, then the pack could at first be used within a test-area, such as the Écoles nationales under the Ministry of Agriculture, to evaluate the benefit to students and teachers, with the objective of modifying the pack for wider distribution later. One thing is clear: if we are in what Hutchinson and Waters describe as the learning-centred phase of education and education research, then the message needs to be broadcast strongly and widely.

\section{BIBLIOGRAPHY}

Allwright, R. L. 1983. Classroom-centered research on language teaching and learning: a brief historical overview. TESOL Quarterly 17/2, 191-204.

Allwright, R.L. 1984. "The importance of interaction in classroom language learning”. Applied Linguistics 5/2, 156-171.

Bransford, J. \& M. Johnson. 1972. "Contextual prerequisites for understanding: some investigations on comprehension and recall”. Journal of Verbal Learning and Verbal Behavior 11, 717-726.

Breen, M. P. \& C. N. 1980. "The essentials of a communicative curriculum in language teaching”. Applied Linguistics 1/2, 89-112.

Brown, J. D. 1988. Understanding Research in Second Language Learning. Cambridge: Cambridge University Press.

Canale, M. \& M. Swain. 1980. "Theoretical bases of communicative approaches to second language teaching and testing". Applied Linguistics 1/1, 1-47.

Chomsky, N. 1957. Syntactic Structures. The Hague: Mouton and Co. 
Chomsky, N. 1959. “Review of Skinner's verbal behaviour”. Language 35, 26-58.

Chomsky, N. 1961. Language and Mind. New York: Panther Books.

Chomsky, N. 1986. Knowledge of Language: Its Nature, Origin and Use. New York: Praeger.

Cohen, A. \& E. Aphek. 1980. "Retention of second language vocabulary over time: investigating the role of mnemonic associations". System 8, 221-235.

Cook, V. J. 1985. Chomsky's universal grammar and second language learning". Applied Linguistics 6/1,2-18.

Day, R. 1984. "Student participation in the ESL classroom or some imperfections in practice". Language Learning 34, 69-102.

Day, R. (ed.). 1986. Talking to Learn: Conversation in second language acquisition. New York: Newbury House.

Doughty, C. \& T. Pica. 1986. "Information gap tasks: Do they facilitate second language acquisition?». TESOL Quarterly 20, 305-325.

Ely, P. 1984. Bring the Lab Back to Life. Oxford: Pergamon.

Ginet, A. et al. 1997. Du laboratoire de langues à la salle de cours multi-médias. Paris: Nathan, 1997.

Harris, T. A. 1967. I'm O.K., You're O.K. London: Arrow Books.

Harris, T. A. \& A. Harris. 1985. Staying O.K. London: Arrow Books.

Hatch, E. 1983. Psycholinguistics: A second language perspective. Newbury House.

Hatch, E. et al. 1986. “The experience model and language teaching”. In Day, R. (ed.), Talking to Learn: Conversation in second language acquisition. New York: Newbury House.

Hayes, A. 1980. Language Laboratory Management: A handbook for teachers. London: British Council.

Heyes, S. et al. 1986. Starting Statistics in Psychology and Education. London: Weidenfield \& Nicholson.

Hutchinson, T. \& A. Waters. 1987. English for Specific Purposes. Cambridge: Cambridge University Press.

Kramsch, C. J. 1991. Interaction et discours dans la classe de langue. Paris : Didier.

Long, M. H. 1981. “Input, interaction and second language acquisition”. In Winitz, H. (ed.), Annals of the New York Academy of Sciences: Native Language and Foreign Language Acquisition 379, 259-278.

McDonough, S. 1995. Strategy and Skill in Learning a Foreign Language. London: Edward Arnold.

Narcy, J.-P. 1991. « Des monologues pour apprendre à communiquer en anglais. Interactions en langue étrangère". In Russier, C. et al. (eds.). Aix: Publications de l'Université de Provence, 1991. Nunan, D. 1989. Designing Tasks for the Communicative Classroom Cambridge: Cambridge University Press.

Nunan, D. 1992. Research Methods in Language Learning. Cambridge: Cambridge University Press.

Ott, C. E. et al. 1973. "The effects of interactive image elaboration on the acquisition of foreign language vocabulary". Language Learning 23/2, 197-206.

Papagno, C. \& G. Vallar. 1992. "Phonological short-term memory and the learning of novel words: The effect of phonological similarity and item length". The Quarterly Journal of Experimental Psychology 44A/1, 47-67. 
Perrin, M. P. 1995. "Les langues de spécialité, facteur de progrès pédagogique". Proceedings of the 10th European LSP Symposium. Vienna : IITF, 47-83.

Pica, T. \& C. Doughty. 1985. "Input and interaction in the communicative classroom: Teacherfronted vs. Group activities". In Gass, S. D. \& Madden, C. (eds.), Input in Second language acquisition. Newbury House.

Pica, T., R. Young \& C. Doughty. 1987. “The impact of interaction on comprehension”. TESOL Quarterly 21/4, 737-758.

Pimsleur, P. \& T. Quinn (eds.). 1971. The Psychology of Second Language Learning. Cambridge: Cambridge University Press.

Porter, P. A. 1986. "How learners talk to each other: input and interaction in task-centered discussions". In Day, R. (ed.), Talking to Learn: Conversation in second language acquisition. New York: Newbury House.

Rivers, W. 1984. Interactive Language Teaching. Cambridge: Cambridge University Press.

Rulon, K. A. \& J. McCrery. 1984. "Negotiation of content: teacher-fronted and small-group interaction". In Day, R. (ed.), Talking to Learn: Conversation in second language acquisition. New York: Newbury House.

Sato, C. J. 1984. "Conversation and interlanguage development: rethinking the connection". In Day, R. (ed.), Talking to Learn: Conversation in second language acquisition. New York: Newbury House.

Schinke-Llano, L. 1984. “Foreigner talk in joint cognitive activities”. In Day, R. (ed.), Talking to Learn: Conversation in second language acquisition. New York: Newbury House.

Seliger, H. W. 1977. "Does practice make perfect? A study of interaction patterns and competence". Language Learning 27, 263-278.

Seliger, H. W. \& E. Shohamy. 1989. Second Language Research Methods. Oxford: Oxford University Press.

Service, E. 1992. "Phonology, working memory, and foreign-language learning”. The Quarterly Journal of Experimental Psychology 45A/1, 21-50.

Slimani, A. 1992. "Evaluation of classroom interaction”. In Alderson, J. C. \& A. Berette, A. (eds.), Evaluating Second Language Education. Cambridge: Cambridge: Cambridge University Press.

Stone, L. A. 1988. Task-based Activities: A communicative approach to language-laboratory use. IALL Production, USA.

Stone, L. A. Undated. Task-based II: More communicative activities for the language lab. IALL, USA.

Swales, J. M. 1990. Genre Analysis. English in academic and research settings. Cambridge: Cambridge University Press.

Wells, G. 1981. Learning through Interaction. Cambridge: Cambridge University Press.

\section{ABSTRACTS}

In the 24-post language laboratory of the National Institute of Horticulture in Angers, we teach modern languages using what we term an interactive method, based on putting non-nativespeaker students into a communication-task-based situation in which they have to communicate in pairs. The learning is of specific language use, in this case scientific or horticultural, using 
information gaps as part of the task procedure. The research carried out here on over 240 students is a comparative test of interactive versus non-interactive learning methods. Shortterm and long-term memory tests are used to analyse statistically the differences between the two groups. Results clearly demonstrate significant advantages for both short-term and longterm memory when interactive learning is used in comparison to non-interactive learning for a two-hour lesson.

$\mathrm{Au}$ laboratoire de langues de l'Institut national d'horticulture d'Angers, nous utilisons une méthode interactive pour l'enseignement des langues étrangères. Le principe de cette méthode est de faire communiquer des paires de locuteurs non natifs placés dans une situation de communication où ils ont des problèmes à résoudre. La recherche menée ici, avec plus de 240 étudiants, est un test comparatif de l'apprentissage interactif et de l'apprentissage non interactif. Des tests de mémoire à long terme et de mémoire à court terme sont utilisés pour faire une analyse statistique entre les deux groupes. Les résultats montrent clairement des avantages significatifs pour la mémoire à long terme et la mémoire à court terme dans une situation d'apprentissage interactif, par opposition à une situation d'apprentissage non interactif pendant un cours de deux heures.

\section{INDEX}

Mots-clés: apprentissage interactif, information lacunaire, locuteur non natif, tâche de communication

Keywords: communication task, information gap, interactive learning, non-native speaker

\section{AUTHOR}

\section{DAVID REES}

David Rees est enseignant d'anglais à l'École nationale d'horticulture d'Angers. Il prépare une thèse sous la direction du professeur J.M. Baïssus à l'Université Paul-Valéry Montpellier 3. david.rees@agrocampus-ouest.fr 